\title{
Effect of $\beta$ TCP filled polyetheretherketone on osteoblast cell proliferation in vitro
}

\author{
L. Petrovic ${ }^{1}$, D. Pohle ${ }^{2}$, H. Münstedt ${ }^{2}$, T. Rechtenwald ${ }^{3}$, K. A. Schlegel ${ }^{1} \&$ \\ S. Rupprecht ${ }^{1, *}$ \\ ${ }^{1}$ Department of Oral and Maxillofacial Surgery, Friedrich-Alexander-University Erlangen-Nuremberg, \\ Glückstr. 11, 91054, Erlangen, Germany; ${ }^{2}$ Department of Materials Science, Institute of Polymer Materials, \\ Friedrich-Alexander-University Erlangen-Nuremberg, Martensstr. 7, 91058, Erlangen, Germany; ${ }^{3}$ Bavarian \\ Laser Center, Konrad-Zuse-Str. 2-6, 91052, Erlangen, Germany
}

Received 19 May 2005; accepted 8 September 2005

(C) 2005 National Science Council, Taipei

Key words: cultivation, human osteoblast, in vitro, PEEK, $\beta$ TCP

\begin{abstract}
Summary
Non-resorbable thermoplastic polymers have become more important for reconstructive surgery due to their excellent chemical and physical properties. Polyetheretherketone- $\beta$-tricalcium phosphate ( $\beta$ TCPPEEK) composites were developed as alternative materials for load-bearing applications. This study presents the effect of polyetheretherketone (PEEK) specimens incorporated with 5, 10, 20 and $40 \mathrm{wt} \%$ $\beta$-tricalcium phosphate $(\beta \mathrm{TCP})$ and processed by injection molding on cultivated osteoblast cells. Normal human osteoblast (NHOst) cells were seeded onto polymer discs to evaluate cell viability and proliferation after 24, 72 and $120 \mathrm{~h}$ of cultivation by employing the WST-1 assay. Standard tissue culture plastic was used as a control. The osteoblast cells were found to be viable in all PEEK groups, while the cell proliferation was progressively inhibited due to the incorporated $\beta$-tricalcium phosphate. $\beta$ TCP-PEEK showed concentration independent decrease of cell proliferation compared to the unfilled PEEK and the control group. In summary, this study confirms the non-toxic nature of pure PEEK, whereas this could not definitely be verified for $\beta$ TCP-PEEK as a composite material in chosen concentrations of $\beta$-tricalcium phosphate in vitro.
\end{abstract}

\section{Introduction}

Sufficient strength and stiffness, biocompatibility and long-term stability are important properties of polymers for successful implant applications in bone replacement. Polyetheretherketone (PEEK) is a semi crystalline thermoplastic, which is characterized by high chemical and thermal stability combined with good strength, stiffness and toughness. Due to these properties pure and carbonfibre reinforced PEEK is used in a wide range of

\footnotetext{
*To whom correspondence should be addressed. Tel.: +499131-85-34201; Fax: +49-9131-85-34219; E-mail: stephan. rupprecht@mkg.imed.uni-erlangen.de
}

medical applications (spinal cages, hip prosthesis, dental implant systems and fracture fixation plates) $[1,2]$. Furthermore PEEK offers additional advantages including its ability to be repeatedly sterilized and shaped readily by machining and heat contouring due to its very high glass transition temperature and a melting point of about $345^{\circ} \mathrm{C}$.

Investigations of composite materials for the development of implants in bone surgery were originated by observations of bone loss around metallic fracture fixation plates [3]. This bone loss was attributed to stress shielding due to the mismatch in modulus of elasticity and stiffness 
between implant and bone, indicating the importance of a strong interface between implant surface and bone [4]. According to reported tissue reactions around PEEK implants, it is believed that this reactions can be avoided by coating PEEK with materials known for their favorable response in bone tissue, such as calcium phosphates. The new bone formation could be observed adjacent to the bone-implant interface in close apposition in vivo [5]. Calcium phosphate compounds have long been the subject of intensive investigation as bone substitutes and several materials consisting of hydroxyapatite, $\alpha$-tricalcium phosphate ( $\alpha \mathrm{TCP})$, or $\beta$-tricalcium phosphate ( $\beta$ TCP) have been clinically applied in various forms [6]. However, by controlling the calcium phosphate ratio in the process of synthesis, ideal calcium phosphate composites can be produced with reasonable solubility and biomechanical strength.

This study aims on investigating the potential of PEEK composites, containing different concentrations of $\beta$ TCP as a possible bone analogue substitutes, suitable for load bearing functions. The tensile properties and the evaluation of osteoblast cell proliferation carried out in vitro will be presented.

\section{Materials and methods}

\section{Characterization and processing of polymer substrates}

The specimens tested in the osteoblast proliferation assays were made of the standard viscosity grade polyetheretherketone PEEK $^{\mathrm{TM}} 450 \mathrm{G}$ (Victrex PLC, Manchester, UK). The physical properties as given by the manufacturer are shown in Table 1.

The polymer matrix was filled with $\beta$-tricalcium phosphate ( $\beta$ TCP, Merck, Darmstadt, Germany), classified as dry and purest, and follows European pharmaceutical guidelines (E141, Ph Eur, British Pharmacy). The grain size given by the manufacturer was stated as $98 \%$ of the particles have a diameter smaller than $63 \mu \mathrm{m}$. Samples with five different filler contents $(0 \mathrm{wt} \%, 5 \mathrm{wt} \%, 10 \mathrm{wt} \%$, $20 \mathrm{wt} \%, 40 \mathrm{wt} \%$ ) were compounded in a twinscrew extruder (Leistritz LSM 34, Nuremberg, Germany). The polymer melt was cooled down in a water bath and then chopped into regular shaped granules with an average size of $3 \mathrm{~mm}$. After drying the $\beta$ TCP-PEEK material at $120{ }^{\circ} \mathrm{C}$ for at least $24 \mathrm{~h}$, it was injection moulded (Arburg Allrounder 320S, Loßburg, Germany) into dumb-bell shaped tensile bars. The parameters were chosen according to the processing instructions of the manufacturer. Tensile testing was performed according to ISO 527 at room temperature using the tensile testing machine Zwick Z 050 (Zwick, Ulm, Germany). A crosshead speed of $10 \mathrm{~mm} / \mathrm{min}$ and a gauge length of $50 \mathrm{~mm}$ were used. To provide an accurate measurement of the elastic modulus a Multisens extensometer (Zwick, Ulm, Germany) was fitted to the specimen.

The discs for the cell culture tests with a diameter of $15 \mathrm{~mm}$ were cut out from the shoulder region of the tensile bars by use of a $\mathrm{CO}_{2}$-Laser. The thickness was about $3 \mathrm{~mm}$. To avoid topological surface effects on cell proliferation all specimens were ground with a P800 silicon carbide paper. The surface of an unfilled PEEK specimen (Figure 1a) and a specimen with $5 \mathrm{wt} \% \quad \beta$ TCP content after the grinding process is shown (Figure 1b) in the scanning electron micrographs (LEO 435VP, LEO Electron Microscopy Ltd., Cambridge, UK). The SEM micrographs show the uniform, regular structure of the polymer surfaces with a roughness and scrub marks below $10 \mu \mathrm{m}$.

\section{Cell culture}

Normal human osteoblasts (NHOst, Cambex Bio Science Verviers, Belgium) were seeded in T-150 culture flasks with fresh culture media ( $\alpha \mathrm{MEM}$, Invitrogen Life Technologies, Germany) supplemented with $20 \%$ fetal calf serum (Gibco BRL, Paisley, Scotland, United Kingdom), $10^{5}$ I.U. penicillin and $100 \mathrm{mg} / \mathrm{l}$ streptomycin (Abbod $\mathrm{GmbH}$, Germany). According to the company,

Table 1. Properties of polyetheretherketone $450 \mathrm{G}$ (PEEK).

\begin{tabular}{ll}
\hline Density (ISO 1183) & \\
$\quad$ Crystalline & $1.32 \mathrm{~g} / \mathrm{cm}^{3}$ \\
$\quad$ Amorphous & $1.26 \mathrm{~g} / \mathrm{cm}^{3}$ \\
Typical cristallinity & $35 \%$ \\
Tensile strength (ISO 527) & $97 \mathrm{~N} / \mathrm{mm}^{2}$ \\
Elastic modulus (ISO 527) & $3.5 \mathrm{GPa}$ \\
Water absorption (ISO 62, saturation) & $0.5 \mathrm{weight}$ \\
Glass transition temperature & $143{ }^{\circ} \mathrm{C}$ \\
Melting point & $343{ }^{\circ} \mathrm{C}$ \\
\hline
\end{tabular}



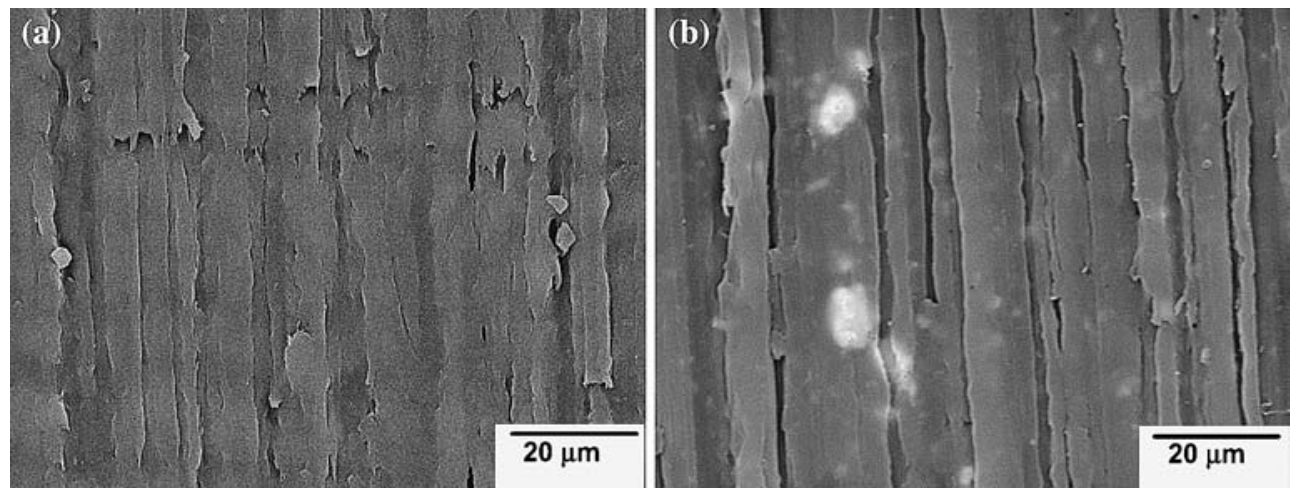

Figure 1. SEM micrographs of the surface of PEEK after grinding with P800 silicon carbide paper (a) unfilled PEEK (b) PEEK filled with $5 \mathrm{wt} \%$ $\beta \mathrm{TCP}$ (white spots).

the cells were alkaline phosphatase-positive and formed von Kossa-positive nodules. Cultures of $90 \%$ confluent cells were trypsinized $(2.5 \mathrm{~g} / 1$ trypsin containing $1 \mathrm{mmol} / 1$ EDTA, Gibco, BRL, Paisley, UK), washed and suspended in fresh media. Twenty thousand cells diluted into $100 \mu \mathrm{l}$ of media were added to the surface of each biomaterial or to an empty well of tissue culture polystyrene (TCPS), and incubated for $30 \mathrm{~min}$ at $37{ }^{\circ} \mathrm{C}$ in humidified $5 \% \mathrm{CO}_{2}$ conditions to allow the cells to adhere. Consecutively $1 \mathrm{ml}$ culture medium was added to cover the biomaterials.

\section{Cell proliferation assay}

Cell proliferation was assessed using the labelling kit WST-1 (ROCHE Diagnostics GmbH, Mannheim, Germany) after 24, 72 and $120 \mathrm{~h}$. The assay is based on the cleavage of the tetrazolium salt WST-1 to formazan by cellular mitochondrial dehydrogenases. Expansion in the number of viable cells results in an increase in the overall activity of the mitochondrial dehydrogenases. The medium was removed and $450 \mu \mathrm{l}$ of fresh medium with $50 \mu \mathrm{l}$ WST-1 labelling solution was added. The determination of cell proliferation was performed after $1 \mathrm{~h}$ in microplate ELISA-reader (Vmax, Molecular Devices, Germany) at absorbance of $450 \mathrm{~nm}$.

\section{Statistical analysis}

All measurements were performed at least five times and expressed as the mean. Single-factor analysis of variance (ANOVA) for multiple comparisons was employed to assess the statistical significance of the data. A $p$-value of less than 0.05 was considered to be significant.

\section{Results}

\section{Mechanical properties}

The observed tensile properties were strongly influenced by the $\beta$ TCP content. The ceramic particle filled polymers showed the typical reinforcement effects. With increasing amount of $\beta T C P$, the elastic modulus increased significantly from 4.1 GPa for unfilled PEEK until a maximum value of $7.2 \mathrm{GPa}$ at $40 \mathrm{wt} \%$ for filled polymers. The tensile strength slightly increased from unfilled PEEK up to a maximum of $94.8 \mathrm{~N} / \mathrm{mm}^{2}$ at $20 \mathrm{wt} \%$, but then drops to $86.6 \mathrm{~N} / \mathrm{mm}^{2}$ for $40 \mathrm{wt} \%$ of $\beta$ TCP. Figures 2 and 3 show the elastic modulus and the tensile strength depending on the $\beta T C P$ content in the PEEK matrix.

\section{Cell proliferation}

When comparing the results with the control group, all groups showed viable cells during the observation period of $120 \mathrm{~h}$, allowing the cleavage of tetrazolium salt WST-1 to formazan by cellular mitochondrial dehydrogenase. The cell population of the control persistently increased with time. The cell population of pure PEEK had the same tendency as that of the control, but during the time of incubation the cell population of pure PEEK was significantly lower than that of the control $(p<0.05)$. 


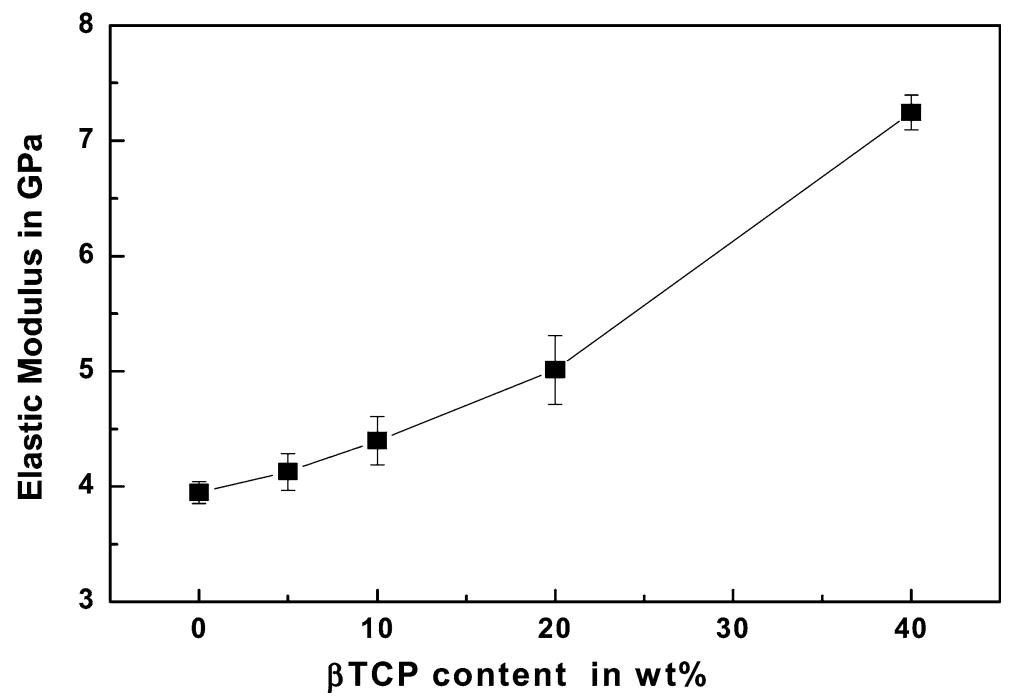

Figure 2. Plot of elastic modulus versus $\beta$ TCP content, presenting the reinforcement effect of the ceramic filler particles.

During the culture period, the cell population of all $\beta$ TCP-PEEK groups were persistently lower than that of the control or pure PEEK $(p<0.05)$. Despite the slightly higher proliferation rate in the $5 \mathrm{wt} \%$ BTCP-PEEK group after $120 \mathrm{~h}$, the inhibition of cell growth was not dependent on the concentration of $\beta$-tricalcium phosphate in the composite $(p>0.05)$. These findings correspond to the growth curves of cells, as shown in Figure 4, demonstrating that none of the $\beta$ tricalcium phosphate compounds supported the proliferation of osteoblast cells in vitro when comparing to the control $(100 \%)$ and the pure PEEK group.

\section{Discussion}

To reduce the number of biomechanical studies, and above all unnecessary animal trials, evaluation of new biomaterials should nowadays begin with in vitro tests. This applies for the development of both temporary and permanent implants and prostheses, and for permanent implants particularly under the aspect that toxic potential is often the consequence of chronic exposure to minute concentrations. The potential of PEEK$\beta T C P$ composites with different amounts of $\beta$-tricalcium phosphate ranging from 5 up to $40 \mathrm{wt} \%$ was demonstrated in this study.

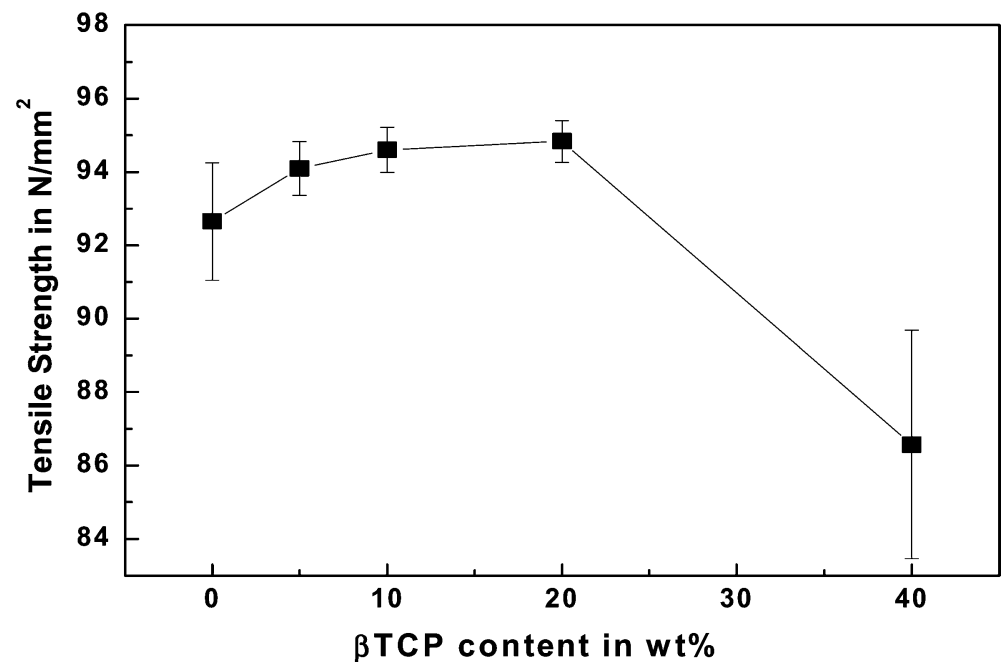

Figure 3. Plot of tensile strength versus $\beta$ TCP content, showing the limitation effect of the high filler contents. 


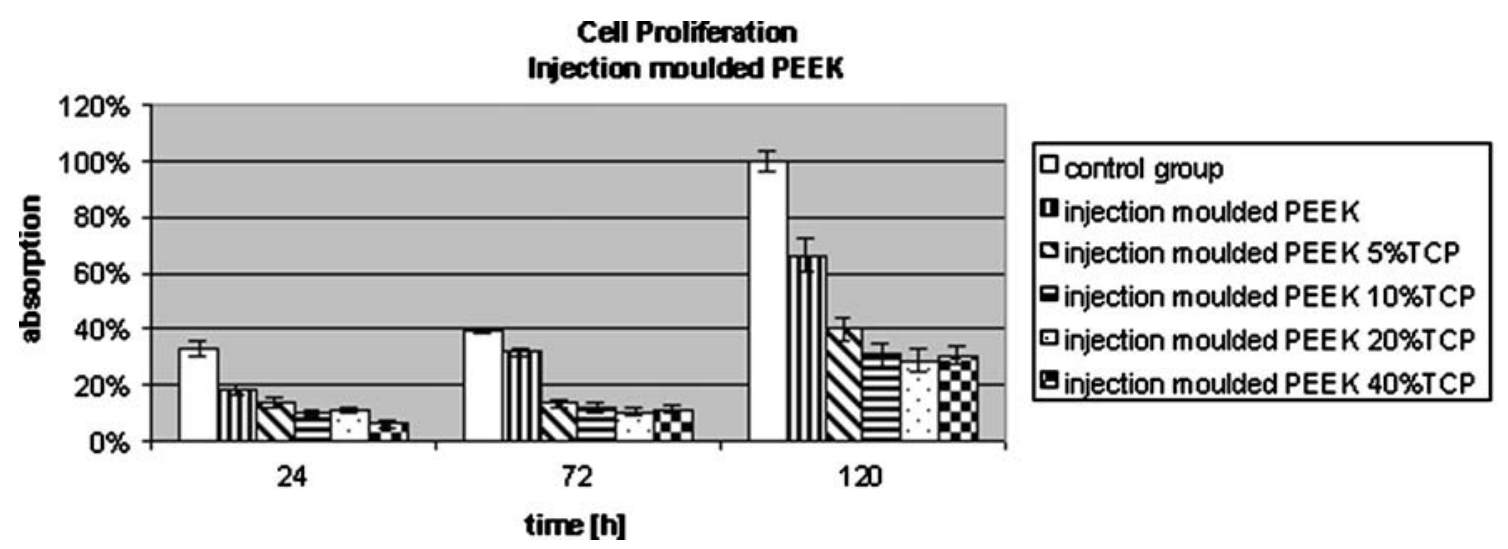

Figure 4. Proliferation of osteoblast cells on injection moulded PEEK with different concentrations of $\beta$ TCP in comparison to the control group expressed as the mean in percent of absorbance.

When evaluating the mechanical properties, it was found that the modulus of PEEK composite lies within the low range of the natural bone modulus which ranges from 4.4 to $30 \mathrm{GPa}$ [7]. The tensile strength of the $\beta \mathrm{TCP}$ composite materials (i.e. $94.8 \mathrm{~N} / \mathrm{mm}^{2}$ at $20 \mathrm{wt} \%$ ) did not reach the strength of natural bone, which is about $117 \mathrm{MPa}$, and decreases with higher filler contents [7].

To make the biomaterials more comparable, the investigated $\beta$ TCP-PEEK specimens were processed with a similar surface structure and a macrointerconnection size minor than $10 \mu \mathrm{m}$ as observed with SEM (Figure 1). To exclude the possibility that results might be influenced by fibre length great care was taken during the cutting of PEEK samples to ensure that the disc were of identical size. Topographical features in the micrometer range can affect activation, adhesion, orientation, morphology and movement of cells and the expression of genes [8]. It has already been considered that not only the chemical properties and the chemical composition, but also the physical quality of a biomaterial surface affects cell-biomaterial interactions by influencing the attachment and subsequent modulation of the intracellular signals that are involved [9-11]. In general cells cultured on rougher surfaces tended to exhibit attributes of more differentiated osteoblasts than did those cells cultured on smoother surfaces for comparable periods, including reduced cell numbers and increased total protein content [12]. Those can be explained by the hypothesis for cells not to colonize on a macropore but to pass through interconnections [13].
The proliferation in the present study was evaluated by WST-1 of cells attached to the PEEK composites discs after a cultivation time of $120 \mathrm{~h}$. According to other studies in the literature detailing aspects of the biocompatibility of PEEK, the results of the present study show that PEEK allows cell proliferation and do not induce cytotoxicity under the chosen study conditions [14]. On the contrary, neither the chemical composition nor the structure of the $\beta$ TCP-PEEK surface was able to modulate or support similar cell proliferation. This has resulted in discussion that calcium phosphate compounds might not have a favorable effect on bone growth. It is very difficult to find a common cause for the inhibition of cell proliferation by calcium phosphates, because the diversity of the specifications of the calcium phosphates makes it difficult to link the biological results obtained with the characteristics of the material $[8,15]$. The mitochondrial cell activity during the total assay was not blocked, showing that $\beta$ TCP-PEEK do not induce cytotoxicity but inhibit the cell proliferation under the chosen study conditions. This finding is in accordance to the results of previous study, which demonstrated that pure $\beta$ TCP has an inhibitory effect on the growth of osteoblast cells in vitro $[16,17]$.

The present study verified the effect of pure PEEK, and pointed out that there is no advantageous effect of PEEK composites containing calcium phosphate on the proliferation of osteoblast cells. More detailed in vitro studies of the precipitated calcium phosphate fillers have to be investigated. 


\section{Conclusion}

The potential of $\beta$ TCP-PEEK composites containing up to $40 \mathrm{wt} \% \quad \beta$ TCP, as a possible bone analogue substitute, has been investigated by observing mechanical characteristics and the effect on osteoblast cell proliferation. It was found, that the mechanical properties of the composite match partly this of human bone. Cell proliferation tests have verified the effect of pure PEEK, but failed to confirm the advantageous effect of PEEK composites containing calcium phosphate on the proliferation of osteoblast cells. The proliferation rates of osteoblasts growing on $\beta$ TCP-PEEK were lower than that of pure PEEK. From these findings, $\beta$ TCP-PEEK is thought to have an inhibitory effect on the growth of osteoblasts in vitro.

\section{Acknowledgements}

The project is founded by The Bavarian Ministry of Economic Affairs, Infrastructure, Transport and Technology as part of the research program 'New Materials'.

\section{References}

1. Cook S.D. and Rust-Dawicki A.M., Preliminary evaluation of titanium-coated PEEK dental implants. J. Oral Implantol. 21: 176-181, 1995.

2. Goldberg A.J., Burstone C.J., Hadjinikolaou I. and Jancar J., Screening of matrices and fibers for reinforced thermoplastics intended for dental applications. J. Biomed. Mater. Res. 28: 167-173, 1994.

3. Terjesen T. and Apalset K., The influence of different degrees of stiffness of fixation plates on experimental bone healing. J. Orthop. Res. 6: 293-299, 1988.

4. Fujihara K., Huang Z.M., Ramakrishna S., Satknanantham K. and Hamada H., Performance study of braided carbon/PEEK composite compression bone plates. Biomaterials 24: 2661-2667, 2003.
5. Abu Bakar M.S., Cheng M.H., Tang S.M., Yu S.C., Liao K., Tan C.T., Khor K.A. and Cheang P., Tensile properties, tension-tension fatigue and biological response of polyetheretherketone-hydroxyapatite composites for load-bearing orthopedic implants. Biomaterials 24: 2245-2250, 2003.

6. Bohner M., Calcium orthophosphates in medicine: from ceramics to calcium phosphate cements. Injury 31(Suppl 4): 37-47, 2000.

7. Currey J., Incompatible mechanical properties in compact bone. J. Theor. Biol. 231: 569-580, 2004.

8. Frayssinet P., Trouillet J.L., Rouquet N., Azimus E. and Autefage A., Osseointegration of macroporous calcium phosphate ceramics having a different chemical composition. Biomaterials 14: 423-429, 1993.

9. Cai K., Yao K., Hou X., Wang Y., Hou Y., Yang Z., Li X. and Xie H., Improvement of the functions of osteoblasts seeded on modified poly(D,L-lactic acid) with poly(aspartic acid). J. Biomed. Mater. Res. 62: 283-291, 2002.

10. Chesmel K.D., Clark C.C., Brighton C.T. and Black J., Cellular responses to chemical and morphologic aspects of biomaterial surfaces. II. The biosynthetic and migratory response of bone cell populations. J. Biomed. Mater. Res. 29: 1101-1110, 1995.

11. Lincks J., Boyan B.D., Blanchard C.R., Lohmann C.H., Liu Y., Cochran D.L., Dean D.D. and Schwartz Z., Response of MG63 osteoblast-like cells to titanium and titanium alloy is dependent on surface roughness and composition. Biomaterials 19: 2219-2232, 1998.

12. Lee S.J., Choi J.S., Park K.S., Khang G., Lee Y.M. and Lee H.B., Response of MG63 osteoblast-like cells onto polycarbonate membrane surfaces with different micropore sizes. Biomaterials 25: 4699-4707, 2004.

13. Bignon A., Chouteau J., Chevalier J., Fantozzi G., Carret J.P., Chavassieux P., Boivin G., Melin M. and Hartmann D., Effect of micro- and macro-porosity of bone substitutes on their mechanical properties and cellular response. J. Mater. Sci. Mater. Med. 14: 1089-1097, 2003.

14. Williams D., New horizons for thermoplastic polymers. Med. Device Technol. 12: 8-9, 2001

15. Ha S.W., Kirch M., Birchler F., Eckert K.L., Mayer J., Wintermantel E., Sittig C., Pfund-Klingenfuss I., Textor M., Spencer N.D., Guecheva M. and Vonmont H., Surface activation of polyetheretherketone (PEEK) and formation of calcium phosphate coatings by precipitation. J. Mater. Sci. Mater. Med. 8: 683-690, 1997.

16. Katzer A., Marquardt H., Westendorf J., Wening J.V. and von Foerster G., Polyetheretherketone-cytotoxicity and mutagenicity in vitro. Biomaterials 23: 1749-1759, 2002.

17. Sun J.S., Tsuang Y.H., Liao C.J., Liu H.C., Hang Y.S. and Lin F.H., The effects of calcium phosphate particles on the growth of osteoblasts. J. Biomed. Mater. Res. 37: 324-334, 1997. 